\title{
Learning Clinical Confrontation from Columbo
}

\author{
Michael W. Kahn, M.D. \\ Harvard Medical School, Rabb-2, BIDMC East Campus, 330 Brookline Ave., Boston, MA, USA.
}

J Gen Intern Med 36(12):3859-60

DOI: $10.1007 / \mathrm{s} 11606-021-06844-Z$

(C) Society of General Internal Medicine 2021

$\mathrm{D}$ octors understandably dislike confronting deceptive patients but must find a way to do so productively. Unlike litigators and prosecutors - whose usual business may require exposing their adversaries' falsehoods - the usual business of physicians requires the presumption of trust. Exposing a patient's lie can feel un-Hippocratic and aggressive and may indeed tempt the doctor to respond harshly rather than helpfully. But clinical confrontation differs significantly from courtroom confrontation. A useful model for the former is provided by the fictional detective Columbo, as portrayed by Peter Falk on television in the 1970s and readily available on YouTube (One compilation of his technique can be found at https://www.youtube.com/watch?v=QxBnaMGP2aY\&t=267s). Doctors can learn some important lessons from this clinician of criminality.

Short and rumpled, with an unpredictable gaze caused by Falk's actual prosthetic eye, Columbo's clinical incisiveness was softened by his disarming demeanor. If Sherlock Holmes is the austere patrician of investigators, Columbo is the affable plebeian-yet they are equals in shrewdness. Like Holmes, Columbo always seems to be enjoying himself when engaging the nefarious. Everything interests him. His signature maneuver is to conclude a friendly chat with a wary suspect by asking about "just one more thing." He then places an iron fist in a velvet glove and innocently asks the suspect his or her opinion about how to reconcile a damning inconsistency. But Columbo prefers truth to moral triumph. He knows that lying is part of being human.

This attitude can be liberating for a treater who is rightly uncomfortable about confronting patients like a district attorney rather than a caregiver. Overworked doctors, and trainees conscious of liability and insecure about their skills, rarely approach possibly deceptive patients with goodwill and forbearance. This too is human.

But if deception can be seen as another clinical finding - albeit an alienating one - the clinician can be at least

Received March 2, 2021

Accepted April 22, 2021

Published online May 7, 2021 partly freed from his or her natural antipathy toward the patient employing it. A foul-smelling infection is another kind of alienating clinical finding, but of course is never taken personally or as the patient's moral failing by the doctor, who understands that facing it is an occupational hazard. Compassion may be facilitated if the clinician can remember when he or she may have shaded the truth a bit with patients in order to reach a desired outcome.

Imagine that there is a differential diagnosis for the causes of deception, the exploration of which can replace aggravation with fascination, as happens for Columbo. For example, the lying patient is typically more desperate than psychopathic, with deceit serving as the last remaining tool of the powerless. This is usually the case for patients trying to manage overwhelming anxiety or craving by insisting on higher doses of benzodiazepines or opiates. The patient with pseudologia fantastica-compulsive lying, about essentially anything - can't help but cause at least some amazement in his doctor, no matter how aggravating he is. Even the malingerer is more desperate than malignant. The investigation and diagnosis of deceit are more effectively pursued by the clinician adopting the Columbo approach rather than the prosecutorial one. What would this mean in practice?

Opiate-related deception is probably the most prevalent variety. The Columbo-inspired doctor would start by trying to develop an atmosphere of trust, as would be done with any patient. The clinician could engage the possibly prevaricating patient in friendly banter regarding the patient's social milieu, learning in the process something about the turmoil in which opiate-dependent patients often find themselves. This would be preparatory to the "just one more thing" moment when the clinician, affecting (if not actually feeling) generosity, looks the patient in the eye and off-handedly says something along the lines of "You know, a funny thing happened that I wanted to share with you... while we were confirming your prescriptions, we learned that you're getting Percocet from Dr. A, Vicodin from Dr. B, and Dilaudid from Dr. C...we had thought you were just getting Demerol from Dr. X, like you said...we couldn't help wondering if you might have an addiction problem... but what do you think is going on?"

Here is the moment of truth. The encounter can go one of two directions, each one clarifying but only one really satisfying. In the more satisfying outcome, the patient realizes that the jig is up, but also sees that the doctor has resisted being punitive or humiliating. This may allow the patient to admit to addiction and accept help for it. Many patients have never had 
the experience of having been found with hand in cookie jar without having been punished, often brutally. Like Jean Valjean with his candlesticks, they can be astonished that someone recognizes that an apparently antisocial act was motivated by survival rather than criminality. Newly allied with the clinician on the basis of honesty, such patients may grab a lifeline thrown to them if they can do so without losing face.

The other possible outcome of the "moment of truth" is similarly clarifying but less happy for both parties. Here the patient gets outraged, feels exposed, becomes hostile, and demands discharge. The patient is free to leave against medical advice if there is no medical contraindication and he refuses his treaters' efforts to re-establish the treatment on grounds of trust. He has confirmed the truth of Mark Twain's observation that "the lie, as a recreation, a solace, a refuge in time of need, the fourth Grace, the tenth Muse, man's best and surest friend, is immortal." Deception has been uncovered, but in a way that shows the doctor's wish to maintain a treatment alliance as well as the patient's dignity. Any guilt the clinician fears feeling for having "exposed" a patient is lessened in this approach, the aim of which is clarity rather than humiliation or triumph.

Clinicians in emergency rooms are often asked to determine whether a patient threatening suicide if not admitted to the hospital is telling the truth or just trying to "manipulate the system." With unknown patients, this is a tricky business and it usually makes sense to err on the side of caution and admit the patient if there is too much uncertainty - the guiding principle being "fool me once, shame on you." But with the patient well-known to staff from similar prior presentations, a Columbo-inspired approach can help cut the knot of uncertainty. Here the clinician, after hearing the patient out in full, says something like "This is really a terrible spot you're in. I'd like to help, but we should get one important thing out of the way first: hospitalization is unfortunately not going to be an option. Let's see if we can find a reasonable plan B" Deflated and with bluff called - but, crucially, with dignity intact - the patient can then usually come up with a list of places where he could spend a night or two.

An important part of Columbo's identity is his uniform, an old beaten-up tan raincoat. Neither the white coat of the clinician/scientist nor the black robe of the judge, it reflects the fact that he knows that, like his antagonists, he too is flawed, and that he solves puzzles by cultivating humility and familiarity rather than relying solely on impersonal logic or stern judgment. Physicians might benefit by incorporating his approach.

Corresponding Author: Michael W. Kahn, M.D.; Harvard Medical School, Rabb-2, BIDMC East Campus, 330 Brookline Ave., Boston, MA 02215, USA (e-mail: mkahn@bidmc.harvard.edu).

Publisher's Note: Springer Nature remains neutral with regard to jurisdictional claims in published maps and institutional affiliations. 